\title{
COMPARISON OF OUTCOME OF TWO PLATE FIXATION WITH ONE PLATE FIXATION ALONG WITH ARCH BAR IN MANAGEMENT OF PARASYMPHYSIS; A RANDOMIZED CONTROL TRIAL.
}

\footnotetext{
1. MDS

Senior Registrar Oral \& Maxillofacial Surgery

Sardar Begum Dental College, Peshawar.

2. BDS, FCPS

Vice Principal, HOD Oral \&

Maxillofacial Surgery

Sardar Begum Dental College

(Gandhara University), Peshawar.

3. BDS

PGT Oral \& Maxillofacial Surgery

Khyber Medical University.

4. BDS, MSc (Endodontic)

Registrar Endodontic

Margalla Institute of Health

Sciences, Rawalpindi.

5. BDS, FCPS

Registrar Operative Dentistry

Demont Dental College Lahore (KEMU).

Correspondence Address:

Dr. Mohammad Umar

Department of Oral \& Maxillofacial

Surgery

Sardar Begum Dental College,

Peshawar.

dr umar80@yahoo.com
}

Article received on:

02/03/2020

Accepted for publication:

$20 / 06 / 2020$
Mohammad Umar ${ }^{1}$, Jawad Ahmad Kundi ${ }^{2}$, Muhammad Sulaiman ${ }^{3}$, Muhammad Zaib Khan ${ }^{4}$, Ali Altaf ${ }^{5}$

ABSTRACT... Objectives: The aim of this study is to compare two plate fixation and one plate along with arch bar in the treatment of parasymphsis, and to analyze the advantages and disadvantages over one another. Study Design: Randomized Clinical Trial. Setting: Department of Oral and Maxillofacial Surgery Sardar Begam Dental College and Northwest General Hospital Peshawar. Period: Over a period of one year from June 2017 to August 2018. Material \& Methods: 60 patients with parasymphysis fracture after diagnosis established on clinical and radiological examination were equally divided into two groups, 30 patients in each. Group (A) were treated with two miniplates, while Group (B) one miniplate along with arch bar under general anesthesia with proper antibiotics coverage in the pre- and post-operative period. Results: The infection rate 4 (13.3\%) patients in Group B while 0 in Group A. No Loosening / fracture of screw or plate occur in any subject in group $A$ at any follow up visit, while it occurred in 4 subjects in group B at 15 days follow up period. 9 patients in Group A and 6 in Group B presented with immediate post of paresthesia, which was reduced to 7 patients in group $A$ and 6 in group B at 15 days follow up, and to 4 patients in Group A and 5 in Group B at 1 month follow up. Similarly, no subject had inferior border misalignment in group $A$ at any follow up period while 3 subjects have immediate post -op inferior border discrepancy in group B and 6 subjects in the same group shows inferior border discrepancy at 15 days, but the overall result of this variable was also statistically non-significant. Conclusion: Isolated mandibular parasymphysis fracture can be treated with either two miniplates or one miniplate along with arch bar for 6 weeks. Both treatment protocol shows advantages and disadvantages with the aim of achieving the best treatment outcome for the patients.

Key words: $\quad$ Arch Bar, Miniplates, Mandible Fracture, Parasymphsis.

Article Citation: Umar M, Kundi JA, Sulaiman M, Khan MZ, Altaf A. Comparison of outcome of two plate fixation with one plate fixation along with arch bar in management of parasymphysis; A Randomized Control Trial. Professional Med J 2020; 27(9):2007-2013. DOI: 10.29309/TPMJ/2020.27.09.4607

\section{INTRODUCTION}

The increasing number of roads traffic accidents and interpersonal violence has led to a significant increase in craniofacial trauma with mandible the second most common fractured bone in facial skeleton. ${ }^{1}$ After angle and condyle fracture, the Symphyseal or Parasymphyseal region is one the most commonly fractured site in mandible accounting for (14-19\%). ${ }^{2}$ The main objectives that should be kept in mind while treating symphysis and parasymphysis fractures in uncompromised patients include absence of pain, improved diet, decrease joint damage, satisfactory dental occlusion, maximal incisal opening $(40 \mathrm{~mm})$ and earlier return to work. ${ }^{3,4,5}$
Treatment of parasymphseal fracture has evolved significantly over the past few decades. Previously mandibular fractures were mostly treated with closed reduction and wire osteosynthesis with also a course of prolonged maxillomandibular fixation were followed, which was challenging in terms of patient compliance and comfort. Therefore, the preferred treatment option introduced was open reduction and internal fixation with titanium hardware ie; plates and lag screw. After the work of champy and Colleagues, the most acceptable treatment option is the use of two miniplates in the region anterior to mental foramina through transoral approach with early mobilization in order to neutralize the compressive forces on the lower border and tensile forces in the alveolar region 
of the fracture segment. 6,7 But the placement of upper miniplate in mandibular parasymphysis fracture is associated with increase of root injuries $(0.47 \%)$ even if monocortical screw are placed. An alternate option could be placement of arch bar on the lower mandibular teeth which acts as a tension band and thereby eliminates the need for upper miniplate and only lower miniplate is placed along with arch bar. $8,9,10$

Therefore, we conducted a study to compare the outcome of two miniplates with one miniplate and arch bar, in terms of post-operative complications and comfort of the patient.

\section{MATERIAL \& METHODS}

After obtaining ethics and research committee approval, a prospective randomized clinical trial was carried out for a period of 1 year (From June 2017 to August 2018) at the Department of Oral \& Maxillofacial Surgery, Sardar Begum Dental College and Hospital, Gandhara University, Peshawar, and also Northwest General Hospital Peshawar Pakistan.

Informed consent was obtained, and patients of both genders within the age group of 20 to 50 years with isolated mandibular fracture involving parasymphysis, were included in the study after detail history, clinical and radiological examination. Fractures with pre-operative infection, associated mandibular defect, fracture of edentulous mandible, parasymphysis with condyle fracture or medically compromised patients and those not willing to return for follow-up were excluded. A total number 60 Patients were randomly assorted into 2 groups, with Group A (30 patients) to be treated with two miniplates and group B (30 patients) to be treated with one miniplate along with arch bar. A standardized data sheet was formulated, and demographic variables and relevant clinical and radiological findings were noted.

\section{PROCEDURE}

All patients were given prophylactic antibiotic amoxicillin $500 \mathrm{mg} 8 /$ hourly but in case of allergic to amoxicillin injection erythromycin $500 \mathrm{mg} 8 /$ hourly was given before the procedure, followed by $1 \mathrm{~g} 2$ times per day for 4 days. All the procedures were carried out under General anesthesia anaesthesia after proper work up by anesthetists. Following strict aseptic precautions, an appropriate intraoral incision (translabial or vestibular), a fracture site was identified, reduced, and after obtaining satisfactory occlusion, temporary maxillomandibular fixation was placed using either Erich's arch bar or Ivy loop eyelet wiring. Fixation was done using 2 miniplates in Group A (Figure-1) or one miniplate along with arch bar for 6 weeks in Group B (Figure-2), using Champy's principle of osteosynthesis. Standard $2 \mathrm{~mm}$ miniplate system having a thickness of $1.5 \mathrm{~mm}$ and screw diameters of $1.7 \mathrm{~mm}$ was be used for both the groups. A watertight wound closure was done and duration of the procedure was noted.

Soft diet was recommended for 6 weeks postoperatively. Patients were followed at $15^{\text {th }}$ post-operative and after 1 month by a blinded senior oral surgeon for post-operative infection, swelling, paresthesia and osseous alignment, occlusion discrepancy, and radiological evaluation of reduction, and fixation. All the data ws recorded on a pre formed proforma. Student's $t$ test was used to compare two miniplates fixation and one miniplate along with arch bar. A value of $P$ less than .05 was considered statistically significant.

\section{RESULTS}

After drop out a total of 30 patients were randomly assorted were included into each group. The most commonly involved group of patients were male of the third decade. Demographic data are given in Table-l.

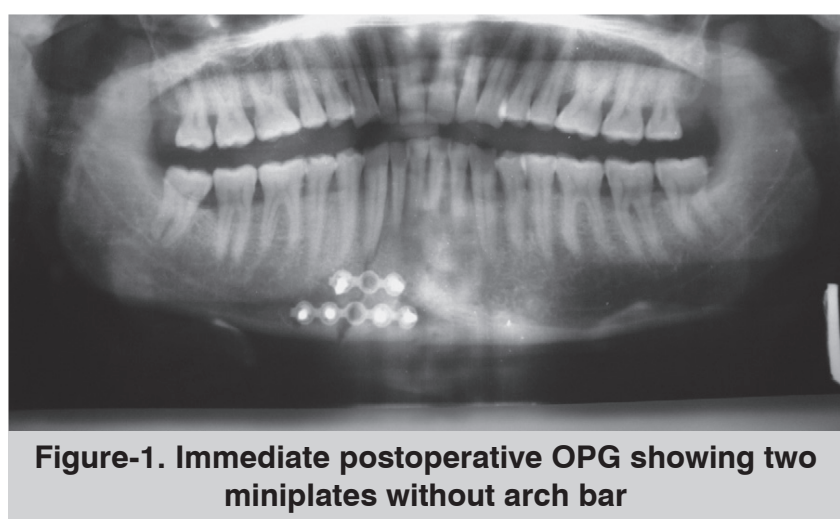




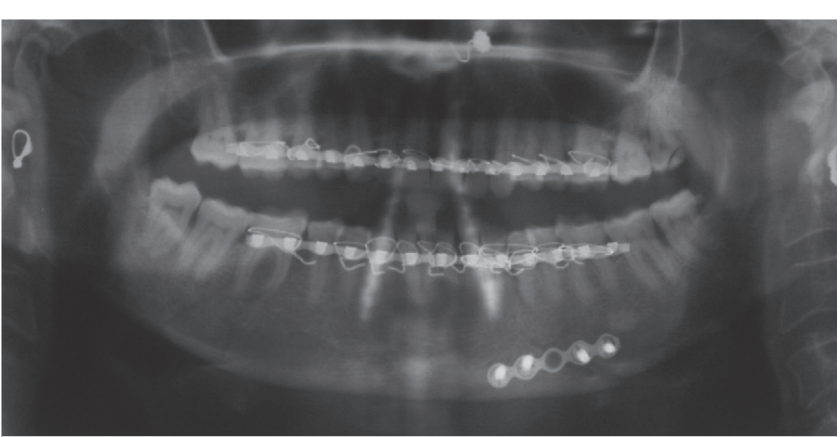

Figure-2. Immediate postoperative OPG showing single miniplates along with arch bar.

\begin{tabular}{|l|c|c|}
\hline $\begin{array}{c}\text { Demographic } \\
\text { Data }\end{array}$ & $\begin{array}{c}\text { Group A } \\
\text { (n_30) }\end{array}$ & $\begin{array}{c}\text { Group B } \\
\text { (n_30) }\end{array}$ \\
\hline $\begin{array}{l}\text { Age, (Mean) } \\
\text { SD }\end{array}$ & $28.83 \pm 13.16$ yrs & $32.36 \pm 13.93 y r s$ \\
\hline $\begin{array}{l}\text { Gender } \\
\text { Male } \\
\text { Female }\end{array}$ & $26(86.7 \%)$ & $27(90 \%)$ \\
\hline
\end{tabular}

Table-I. Demographic data of study patients

There was no signs and symptoms of postoperative infection noted in group $A$, while 4 (13.3\%) patients in Group B presented with postoperative infection which was treated by draining the pus, wound debridement and antibiotics for 5 days (Amoxicillin 500mg 3 times a day and metronidazole 400mg 3 times a day). The overall infection rate in both the groups was $4(6.7 \%)$.

Effectiveness between the two groups were checked by considering variables i.e.; (loosening/ fracture of screw or plate, Sign \& symptom of paresthesia, inferior border misalignment and occlusal discrepancy), and are summarized in Table-Il.

None of the patient in both groups presented with fractured and loosening of screw or plate on the first post-op day. None of the patient in Group A reported with have loosening /fracture of screw or plate at 15 days follow up while In Group B, $4(13.3 \%)$ reported with the same complaint with a significant $P$ value of 0.038 . At 1 month follow up, none of the patient reported with fracture or losing of plate and screw.

Immediate post of paresthesia was $9(30 \%)$ patients in Group A and 6(20\%) in Group B presented with a significant $P$ value of 0.371 , while at 15 days follow up, it was $7(23.3 \%)$ in group A and 6(20\%) in group B subjects with insignificant $P$ value of 0.754 . At 1 month follow up period, it was reduced to 4(13.3\%) in Group A while 5(16.7\%) in Group B with a non-significant $P$ value of 0.71 .

Inferior border misalignment was 0 in Group A and $3(10 \%)$ in Group B in the immediate postoperative period with a non- significant $P$ value of 0.076 . At 15 days follow up period it was $6(20 \%)$ in Group B and 0 in group A with a significant value of 0.010 , while at 1 month follow up it was 0 in both the groups.

Occlusal discrepancy was $7(23.3 \%)$ in Group A and 2(6.7\%) Group B in immediate post-operative period with $P$ value of 0.071 . At 15 days follow up period it was $7(23.3 \%)$ in Group A while 4(13.3\%) in Group B with non-significant P value of 0.317 , while at 1 month follow up it was $7(23.3 \%)$ in Group A and $1(3.3 \%)$ in group B with a significant $P$ value of 0.02 . Comparison of variables with $P$ values are summarized in Table-II.

\section{DISCUSSION}

Most frequent form of therapy provided by oral and maxillofacial surgeons is the treatment of mandibular fracture and Symphyseal or Parasymphyseal region is one the third most commonly fractured site (14 -19\%) after angle and condyle. ${ }^{11,2}$ Therefore, the treatment should be aimed to restore the pre-injury form \& function with least disability and shortest recovery period. ${ }^{12}$

In 1970 miniplates were introduced to the maxillofacial surgery. Miniplates were comparatively thinner than compression plates and monocortical screws were used to provide semi -rigid fixation to the fracture site. The main functional advantages of miniplates were improved jaw function in terms of mouth opening, decrease weight loss, bite force and improved pulmonary function. 


\begin{tabular}{|c|c|c|c|c|c|c|c|}
\hline \multirow[t]{2}{*}{ Variables } & \multicolumn{2}{|c|}{$\begin{array}{l}\text { Immediate } \\
\text { Post-Op }\end{array}$} & \multicolumn{2}{|c|}{15 Days Follow up } & \multicolumn{2}{|c|}{1 Month Follow up } & \multirow[t]{2}{*}{ P-Value } \\
\hline & $\begin{array}{l}\text { Group } \\
\text { A (n_30) }\end{array}$ & $\begin{array}{l}\text { Group B } \\
\text { (n_30) }\end{array}$ & $\begin{array}{c}\text { Group A } \\
\text { (n_30) }\end{array}$ & $\begin{array}{c}\text { Group B } \\
\text { (n_30) }\end{array}$ & $\begin{array}{c}\text { Group A } \\
\text { (n_30) }\end{array}$ & $\begin{array}{l}\text { Group B } \\
\text { (n_30) }\end{array}$ & \\
\hline $\begin{array}{l}\text { Loosening/fracture } \\
\text { Of screw/plate }\end{array}$ & 0 & 0 & 0 & $413.3 \%$ & 0 & 0 & $0.038^{*}$ \\
\hline Sign /symptom of paresthesia & $9(30 \%)$ & $6(20 \%)$ & $7(23.3 \%)$ & $6(20 \%)$ & $4(13.3 \%)$ & $5(16.7 \%)$ & $\begin{array}{c}0.371^{\star} \\
0.754^{\star *} \\
0.71^{\star \star *}\end{array}$ \\
\hline Inferior border misalignment & 0 & $3(10 \%)$ & 0 & $6(20 \%)$ & 0 & 0 & $\begin{array}{l}0.076^{*} \\
0.010^{* *}\end{array}$ \\
\hline Occlusal discrepancy & 7 (23.3\%) & $2(6.7 \%)$ & 7 (23.3\%) & $4(13.3 \%)$ & 7 (23.3\%) & 1 (3.3\%) & $\begin{array}{c}0.071^{\star} \\
0.317^{\star *} \\
0.02^{\star * *}\end{array}$ \\
\hline \multicolumn{8}{|c|}{$\begin{array}{l}\text { Table-II. Variable analysis in the post-op follow up period } \\
\text { post-operative period }\end{array}$} \\
\hline
\end{tabular}

Many other advantages are considered including patient comfort, improved speech and oral hygiene, leading to enhance social interaction of the patient which has a psychological impact on recovering and also there are decrease number of hospitals visit. ${ }^{13,14}$

Miniplates placed according to champy 's ideal lines of osteosynthesis should be placed within $10 \mathrm{~mm}$ of superior boarder but in the anterior part of the mandible, in front of premolar the torsional movements were greater and near the mandibular symphysis they were higher. Therefore, a strong solid plate should be placed on the lower border with additional torsional forces are opposed anterior to the mental foramen by placing another plate $4-5 \mathrm{~mm}$ above this in the subapical plate. Hence these two plates counteracted the compressive and torsional forces there is no need for inter-maxillary fixation. ${ }^{15}$ But, placing two miniplates is expensive for the patient and it increase the chances of injury to the teeth roots, mental nerve injury, chances of infection because of the presence of two foreign bodies instead of one and exposure of osteosynthesis implant material.

Champy et al didn't advise intra or postoperatively intermaxillary fixation, but most surgeons require intermaxillary fixaton for a short period of time either intraoperatively or postoperatively. So, if arch bar is routinely placed in open reduction cases for mandibular fractures then the need for lower arch bar at the tension band for parasymphysis fractures is questioned. This will eliminate the need of two miniplates in the parasymphysis region. ${ }^{15}$ In present study present the outcome of two plates are compared with one plate along with arch bar.

Rix et al followed Champy's principle, but he used a modification for the parasymphysis fracture. linstead of two plates, only one plate was placed above the foramen and supplemented with loop wiring around two or more teeth on either side of the fracture line their results were significant even with the use of this modification. ${ }^{15}$ In the present study, single miniplates with arch bar instead of loop wiring were used and the overall results were non-significant.

In a study by $\mathrm{Al}$-Belasy ${ }^{16}$, conventional 6 weeks maxillomanddibular fixation was compared with another group who had maxillomandibular for 2 weeks followed by arch bar wired to the lower jaw. He found this method effective but, in the present study group B included patients with lower arch bar along with single miniplate which gave satisfactory results with some variables and unsatisfactory in others.

Post -op infection was evaluated in terms of swelling/redness, discharging sinus, fever, pain, foul smell. These five variables were assessed 
separately for all patients. In this study and swelling/ redness and pain is mostly present in all patients. So those patients who have at least three of these variables present in them falls in the criteria of having post-op infection. The infection rate was 4 (13.3\%) patients in Group B while 0 in group $A$. There, overall infection rate in both the groups was $4(6.7 \%)$. Result of this is supported by the above mentioned studies by saluja et $\mathrm{al}^{17}$ and others in which patients treated with one miniplate with arch bar have more post -op infection (10\%) than those patients treated with two miniplates and this is because of the of intra oral hardware use and also movement occcuring between fracture segment which is more than desired. Presence of arch bar increase the chances of periodontal diseases resulting in increase bone loss and also it hinders proper cleaning of the teeth which plays and important role in the healing of incision wound.

Loosening/ fracture of screw or plate occur in 4 patients (13.3\%) in group $B$ at 15 days follow up and group A patients have no loosening / frcature of screw or plate at any follow up visit. These results were exactly the same as in the study by saluja et $\mathrm{al}^{17}$ in which loosening of implanted material occur in one out of 10 patients treated with one miniplate with arch bar at 3 month folow up, no patient in the group treated with two miniplates in the parasymphysis reagion but statistically no radiographic values were significant $(p>0.05)$ which support the fact that two miniplates are better able to resist torsional force present in the parasymphysis region than that by arch bar. So, statistical analysis of this study shows that arch bar are not as effective as miniplate placed in the subapical rgion of the teeth in the parasymphysis fracture. So statistical analysis of loosening/ fracture of screw or plte give significant value.

Out of 30 only 6 patients in group B had immediate post op and 15 days follow up anesthesia or paresthesia and 5 patient in the same group have sign / symptom of anesthesia at 1 month follow up and in group A treated with 9 patients have immediate post op paresthesia and 7 patients at 15 days and 4 patients at 1 month follow up visit shows sign /symptom of paresthesia. This is because in placing two miniplates in the area closest to the mental nerve specially that upper miniplate which is placed in the sub-apical area of the tooth the operator needs to manupuliate that area far more than if the arch bar is placed instead of that plate. Because of increase manipulation of parasympsis region group A shows more subjects that are taking more time to recover from paresthesia. This result is supported in the studies by Saluja et $\mathrm{al}^{17}$, in which treatment protocol influence the resultant post-op sign / symptom of paresthesia with more subjects treated with two miniplates shows prolonged paresthesia as compared to the group treated with one miniplate with arch bar.

The inferior border discrepency was observed and 3 patients $(n=30)$ in group $B$ have immediate postop inferior boarder discrepency and the resultant increase in the subjects in the same group $B$ to 6 at 15 days follow up, while in the group $A$ none of the subject showed inferior border discrepency / malignment. The result of this variable in this study can be supported by the study by Kumar et $\mathrm{al}^{18}$ in which inferior border discrepency / malignment was observed in 5 patients in group treated with one miniplate along with arch bar. This shows that by placing arch bar is not as functionally stable as 2 miniplates in the parasymphysis region of the mandible. This is because the fixation achieved is not as functionally stable as required so that forces generated during function of the mandible can be resisted and also the torsional forces present in the parasymphysis region of the mandible results in inferior border discrepency /malignment.

In our study 7 patients in group A have occlusal discrepency at immediate post op, 15 days and 1 month. While in group B occlusal discrepency was shown by 2 subjects in immediate post -op period, 4 subjects at 15 days follow up period and 1 subject at one month follow up period. By comparing our study with the above studies especially in the study by Saluja et $\mathrm{al}^{17}$ it was seen that occlusal discrepency occur more in subjects treated with 2 miniplates instaed of one miniplate with arch bar because by placing two miniplates in parasymphysis frcature we get a semi- rigid fixation. So after the reduction and fixation of the 
parasymphysis fracture with two miniplates this fracture segment is functionlly stable and retains it position were it is surgically reduce even if there is minor or major occlusal discrepency present which if minor is corrected by selective occlusal grinding. In this study in group B treated with one miniplate along with arch bar, the study by saluja et $\mathrm{al}^{17}$ support the fact that the fixation is not functionally stable as previously discussed, so after reduction and fixation of fracture segment if there is minor occlusal disprepency it self correct or reposition itself or times requires occlusal reduction.

\section{CONCLUSION}

The outcome of the present study suggested that isolated parasymphysis fractures can be managed by using both techniques ie; two miniplates placed in the mandibular parasymphysis fracture region which reduces the chances of loosening or fracture of screw of plate because the load is equally shared, and this in return leads to less post-op infection. Secondly, mandibular parasymphysis fracture can also be treated with a single miniplate along with an Erich arch bar for 6 weeks, which will act as a tension band. The use of single miniplate causes minimum injury to the mental nerve in the case of a fracture line running close to the mental foramen.

It can be concluded that though miniplates are best placed following Champy's principle, isolated parasymphysis fractures can also be managed by putting a single miniplate at the inferior border and utiliz-ing the arch bar as a tension band for 6 weeks.

Copyright $(20$ June, 2020.

\section{REFERENCES}

1. Gandhi S, Ranganathan LK, Solanki M, Mathew GC, Singh I, Bither S. Pattern of maxillofacial fractures at A Tertiary Hospital in Northern India: A 4 year retrospective study of 718 patients. Dental traumatology. 2011; 27(4):257-62.

2. Lee T, Sawhney R, Ducic Y. Miniplate fixation of fractures of the symphyseal and parasymphyseal regions of the mandible: A review of 218 patients. JAMA facial plastic surgery. 2013; 15(2):121-5.
3. Kumar S, Prabhakar V, Rao K, Brar R. A comparative review of treatment of $\mathbf{8 0}$ mandibular angle fracture fixation with miniplates using three different techniques. Indian Journal of Otolaryngology and Head \& Neck Surgery. 2011; 63(2):190-2.

4. Miloro M, Ghali G, Larsen P, Waite P. Peterson's principles of oral and maxillofacial surgery: $\mathrm{PMPH}$ USA; 2004.

5. Patrocínio LG. Mandibular fracture: Analysis of 293 patients treated in the Hospital of Clinics, Federal University of Uberlândia. Brazilian $J$ Otorhinolaryngology 2005; 71 (5): 560-65.

6. Champy M, Loddé J P, Schmitt R, et al. Mandibular osteosynthesis by miniature screwed plates via a buccal approach. J Maxillofacial Surg 1978; 6:14-21.

7. Champy M, Lodde J, Jaeger J, Wilk A. Mandibular osteosynthesis according to the Michelet technic. I. Biomechanical bases. Revue de stomatologie et de chirurgie maxillo-faciale. 1975; 77(3):569-76.

8. Borah GL, Ashmead D. The fate of teeth transfixed by osteosynthesis screws. Plastic and reconstructive surgery. 1996; 97(4):726-9.

9. Fabbroni G, Aabed S, Mizen K, Starr D. Transalveolar screws and the incidence of dental damage: $A$ prospective study. International journal of oral and maxillofacial surgery. 2004; 33(5):442-6.

10. Hussain S, Mohammad S, Khan R. Effectiveness of ORIF by using one Titanium Plate and Archbar for management of mandibular fractures in parasymphyseal region. 2008; 66(11):2254-60.

11. FellerK-U,Richter G, Schneider M, EckeltU. Combination of microplate and miniplate for osteosynthesis of mandibular fractures: An experimental study. International journal of oral and maxillofacial surgery. 2002; $31(1): 78-83$.

12. Souyris F, Lamarche J, Mirfakhrai A. Treatment of mandibular fractures by intraoral placement of bone plates. Journal of oral surgery (American Dental Association: 1965). 1980; 38(1):33-5.

13. Fordyce A, Lalani Z, Songra A, Hildreth A, Carton A, Hawkesford $\mathrm{J}$. Intermaxillary fixation is not usually necessary to reduce mandibular fractures. British Journal of Oral and Maxillofacial Surgery. 1999; $37(1): 52-7$.

14. Brown J, Grew N, Millar B. Intermaxillary fixation compared to miniplate osteosynthesis in the management of the fractured mandible: An audit. British Journal of Oral and Maxillofacial Surgery. 1991; 29(5):308-11. 
15. Rix L, Stevenson A, Punnia-Moorthy A. An analysis of $\mathbf{8 0}$ cases of mandibular fractures treated with miniplate osteosynthesis. International journal of oral and maxillofacial surgery. 1991; 20(6):337-41.

16. Al-Belasy FA. A short period of maxillomandibular fixation for treatment of fractures of the mandibular tooth-bearing area. Journal of oral and maxillofacial surgery. 2005; 63(7):953-6.
17. Saluja H, Dehane V, Kini Y, Mahindra U, Gaikwad P. Use of miniplates in parasymphysis fractures: A survey conducted among oral and maxillofacial surgeons of India. Journal of maxillofacial and oral surgery. 2013; 12(3):312-4.

18. Kumar S, Prabhakar V, Rao K, Brar R. A comparative review of treatment of $\mathbf{8 0}$ mandibular angle fracture fixation with miniplates using three different techniques. Indian Journal of Otolaryngology and Head \& Neck Surgery. 2011; 63(2):190-2.

\begin{tabular}{|c|l|l|l|}
\hline \multicolumn{3}{|c|}{ AUTHORSHIP AND CONTRIBUTION DECLARATION } \\
\hline Sr. \# & \multicolumn{1}{|c|}{ Author(s) Full Name } & \multicolumn{1}{|c|}{ Contribution to the paper } & Author(s) Signature \\
\hline 1 & Mohammad Umar & Conception of idea. \\
\hline 2 & Jawad Ahmad Kundi & Study designing. \\
\hline 3 & Muhammad Sulaiman & Technical considerations. \\
\hline 5 & Muhammad Zaib Khan & $\begin{array}{l}\text { Technical writing and } \\
\text { reviewing. } \\
\text { Data analysis. }\end{array}$ \\
\hline
\end{tabular}

